\title{
Metropolização Contemporânea: transformações territoriais nas metrópoles da América Latina
}

\section{Lúcia Camargos Melchiors ${ }^{1}$}

\begin{abstract}
1 Doutoranda no Programa de Pós-Graduação em Planejamento Urbano e Regional da Universidade Federal do Rio Grande do Sul, Mestrado em Planejamento Urbano e Regional pela Universidade Federal do Rio Grande do Sul, Especialização em Patrimônio Cultural em Centros Urbanos e Arquiteta e Urbanista formada pela Universidade Federal do Rio Grande do Sul. Foi professora nos cursos de Arquitetura e Urbanismo da UNIVATES, da UNIFIN e professora substituta no Departamento de Urbanismo da Universidade Federal do Rio Grande do Sul (UFRGS), Brasil. E-mail: luciacmelchiors@gmail.com
\end{abstract}

RESUMO: Nas últimas décadas, as metrópoles passaram por profundas transformações urbanas. As novas tecnologias da informação e comunicação e o novo enfoque de governança baseado na ampla liberalização econômica impulsionaram diversos e significativos efeitos no espaço metropolitano e uma progressiva e generalizada ampliação mundial do espaço de acumulação, tornando as grandes aglomerações urbanas "nós" de uma rede global. O presente artigo discute os efeitos da globalização sobre as metrópoles latino-americanas, analisando seus impactos no processo contemporâneo de metropolização. Busca-se avaliar a generalidade capitalista e suas particularidades, identificando semelhanças e diferenças nas transformações físicas das metrópoles da América Latina. Adota-se a revisão bibliográfica como processo metodológico fundamentando-se a discussão em autores da geografia (Capel, Janoshcka, Borsdorf, Hildago) e do urbanismo (Pradilla Cobos, Mattos). Sob a ótica deste fenômeno capitalista, são discutidas as principais tendências identificadas nessas transformações urbanas: a) decomposição produtiva e mudanças nos padrões de mobilidade; b) surgimento de uma nova forma urbana difusa e fragmentada; c) existência de novos comportamentos locacionais de empresas e famílias formando ilhas urbanas; d) mudanças na estrutura metropolitana tendendo ao policentrismo; e) existência de um sistema econômico e urbano fortemente baseado em redes; f) contrastes morfológicos; g) importância do reforço de identidades; h) instrumentos de planejamento; e i) dinâmicas dos movimentos sociais. Defendese que as metrópoles atuais latino-americanas seguem as determinações do padrão neoliberal de acumulação, porém a esses se juntam particularidades características da região.

Palavras-chave: metropolização; metrópoles latino-americanas; globalização; transformações urbanas.

\section{Contemporary metropolization: territorial transformations in the Latin American's me- tropolises}

\begin{abstract}
In the last decades the metropolises have undergone profound urban transformations. The new information technologies and communication and the new governance approach based on the broad economic liberalization spurred many and significant effects in the metropolitan space and a progressive and widespread global expansion, making the large urban agglomerations "nodes" in the global network. This article discusses the effects of globalization on Latin American's metropolises analyzing its impact on the contemporary process of metropolization. This article aim to analyse the capitalist generality and its particularities, identifying similarities and differences in the
\end{abstract}


physical transformation of cities in Latin America. The literature review is adopted as the methodology basing the discussion on authors of geography (Capel, Janoshcka, Borsdorf, Hildago) and urbanism (Pradilla Cobos, Mattos). From the perspective of this capitalist phenomenon the main trends identified in the urban transformations are: a) productive decomposition and changes in the mobility patterns; b) emergence of a new urban form: diffuse and fragmented; $c$ ) existence of new locational behavior of firms and households forming "urban islands"; d) changes in the metropolitan structure tending to polycentric; e) economic and urban system strongly based on networks; f) morphological contrasts; g) importance of strengthening identity; h) planning tools; i) dynamics of social movements. It is argued that the current Latin American metropolises follow the determinations of the neoliberal accumulation pattern, but these features come together with particularities of the region.

Keywords: metropolization; Latin American metropolis; globalization; urban transformations.

\section{INTRODUÇÃO}

Nas últimas décadas, as metrópoles passaram por profundas transformações urbanas. A partir da década de 1970, sob os efeitos do novo sistema tecnológico articulado em torno de novas tecnologias da informação e comunicação e do novo enfoque de governança baseado na ampla liberalização econômica, se pôs em marcha uma nova fase de modernização capitalista, que se instalou em praticamente todo o mundo e impulsionou diversos e significativos efeitos no espaço metropolitano (MATTOS, 2010).

Produziu-se uma progressiva e generalizada ampliação mundial do espaço de acumulação, entendido como o processo de Globalização (MATTOS, 2010). Nesse, as grandes aglomerações urbanas se tornaram protagonistas e passaram a funcionar como "nós" de uma rede global, tendo que se adaptar a este novo cenário mundial. Assim, vê-se que as metrópoles atuais passam por um intenso processo de descentralização e reestruturação produtiva, inserido-se em redes cada vez mais densas e internacionalizadas (KLINK, 2008; MAGALHÃES, 2008; SOARES; SCHNEIDER, 2012). Se intensificam e se alteram, desta forma, as dinâmicas da rede urbana e os fluxos de bens, serviços, mercadorias e pessoas existente entre os municípios.

Porém, os efeitos da globalização não são os mesmos nas diferentes partes do mundo. Nos interessa aqui, entender o cenário de transformação das metrópoles latino-americanas e os efeitos deste processo contemporâneo de metropolização. Busca-se analisar a generalidade capitalista e suas particularidades, identificando semelhanças e diferenças nas transformações físicas das metrópoles da América Latina.

A partir de uma revisão bibliográfica de autores que abordam transformações nas metrópoles latino-americanas, em especial os trabalhos de Janoshcka (2002); Janoshcka (2005); Capel (2003); Borsdorf (2003); Mattos (2010); Hidalgo (2012) e Pradilla (2014), procura-se identificar mudanças comuns observadas nas metrópoles latinoamericanas afetadas pelas dinâmicas da globalização. 
Para organização do texto, primeiramente se discute o fenômeno da globalização na América Latina e a seguir são descritas e tratadas, em tópicos, as principais transformações identificadas nas metrópoles contemporâneas.

\section{A AMÉRICA LATINA SOB OS EFEITOS DA GLOBALIZAÇÃO}

A partir das décadas de 1970/1980, as grandes aglomerações urbanas latinoamericanas, inseridas no processo de globalização, passaram por profundas modificações que alteraram sua organização, seu funcionamento, sua morfologia e sua aparência. Essa "metamorfose" das cidades acarretou no desaparecimento de alguns atributos da forma urbana anterior, da cidade industrial, e fortaleceu outros fenômenos e novas tendências (MATTOS, 2010).

Essas modificações urbanas foram impelidas por mudanças tecnológicas, ideológicas e econômicas. No plano tecnológico, a difusão das Tecnologias de Informação (TIC) proporcionou novas formas, mais potentes e eficazes, de conectividade e de mobilidade mundial permitindo um descolamento territorial por todo o planeta. No plano teórico-ideológico, a criação de uma nova matriz de poder social impulsionou um esforço sistemático de liberalização econômica, acarretando em uma desfronteirização do territórios nacionais e contribuindo para a constituição de um espaço supranacional de acumulação (MATTOS, 2010). Assim, a nova fase de modernização capitalista possibilitou a abertura das fronteiras nacionais, aumentando as redes globais.

Com a globalização, viu-se uma diluição do papel do Estado, passando de controlador à facilitador da atuação privada; uma economia do território transformada pela livre iniciativa e pelo livre mercado; o fortalecimento do capital financeiro nacional e estrangeiro que se constituiu em um marco de livre fluxo internacional de capitais; além de um novo papel transformador do capital privado.

$\mathrm{O}$ padrão neoliberal imposto à maioria das nações pelos diversos organismos internacionais (FMI, OMC, Banco Mundial) criou generalidades e traços comuns às cidades do mundo, porem a esses se somam recursos herdados de cada sociedade e as particularidades regionais, como discute Pradilla Cobos (2014). O autor salienta a crescente distinção de desenvolvimento capitalista existente entre os países hegemônicos imperialistas e os países dominados e atrasados, nos quais as desigualdades tem se acentuado. A América Latina ocupa um lugar subordinado no cenário mundial, assim, seus processos de desenvolvimento capitalista e de urbanização não foram os mesmos existentes na Europa ou Estados Unidos, ocorreram em tempos e ritmos diversos, originando cidades e sistemas urbanos também distintos (PRADILLA, 2014).

A América latina possui traços históricos específicos: a subsistência de núcleos indígenas no campo e nas cidades, a urbanização acelerada fruto do intenso processo migratório do campo-cidade entre a década de 1940-1980, uma industrialização tardia seguida de uma desindustrialização prematura, a presença recorrente de ditadu- 
ras militares e regimes de exceção ocorridos na região ao longo dos anos 1970, a atual diversidade (no discurso ou real) de posturas governamentais anti neoliberais, a autoconstrução maciça de habitação popular desde a década de 1940, a formação de um mercado informal do solo e da habitação, a informalidade como atividade laboral de subsistência frente ao enorme desemprego estrutural e a probreza, a violência urbana generalizada nas cidades devida, em grande parte, ao narcotráfico e sua incidência na vida urbana (PRADILLA, 2014).

A partir da década de 1970, viu-se nas metrópoles latino-americanas os efeitos da globalização acarretando transformações sociais e políticas que modificaram seu desenvolvimento urbano, acompanhados pela redução das migrações do campo para a cidade (JANOSHCKA, 2002). A política neoliberal nesse contexto teve como eixo estruturador a eliminação de subsídios e a redução dos gastos públicos (PRADILLA, 2014). Na década de 1990 reformas econômicas limitaram a capacidade de gestão estatal mediante privatizações de empresas publicas e o desmantelamento do sistema social (JANOSHCKA, 2002). Essa privatização do público, que se faz presente nos mais diversos âmbitos do urbanos (solo, imóveis, praças, parques, serviços sociais, etc)., tem sido mais acelerada, profunda e extensa nos países latino-americanos em comparação aos países hemegônicos. Apresenta-se assim, um amplo e profundo processo de mercantilização dos elementos da estrutura urbana que, com o abandono da gestão e do controle do desenvolvimento urbano por parte do Estado, tem sua apropriação substanciada pelo Setor Privado, dando origem à aparição de formas urbanas comercializáveis e valiosas principalmente para o mercado (JANOSHCKA, 2002; PRADILLA, 2014).

Sob a ótica deste fenômeno capitalista, e seus efeitos globalizantes, foram selecionadas tendências identificadas nas transformações urbanas sofridas pelas metrópoles contemporâneas na América Latina. Elas são: a) o processo de decomposição produtiva e de mudanças nos padrões de mobilidade; b) o surgimento de uma nova forma urbana da cidade difusa e fragmentada; c) a existência de novos comportamentos locacionais de empresas e famílias e a formação de ilhas urbanas; d) mudanças na estrutura metropolitana tendendo ao policentrismo; e) a existência de um sistema econômico e urbano fortemente baseado em redes; f) os contrastes morfológicos das metrópoles; g) a importância do reforço de suas identidades; h) os instrumentos de planejamento; e i) as dinâmicas dos movimentos sociais.

\section{a) Decomposição produtiva e mobilidade: efeitos sobre a organização urbana}

As alterações do processo de acumulação capitalista modificaram também as dinâmicas e estratégias empresariais. Para aumentar sua competitividade, diversas empresas passaram por um processo paulatino de reestruturação de seus processos produtivos (em subprocessos) e dispersaram suas atividades em significativo número de filiais espalhadas nas grandes áreas urbanas de diferente países (MATTOS, 2010). Essa estratégia, seja para minimizar custos unitários ou para ampliar o mercado, acar- 
retou um espaço de acumulação de cobertura mundial que condiciona a dinâmica essencial da globalização (MATTOS, 2010).

Assim, as mudanças na base econômica geraram alterações em um número significativo de áreas urbanas que, inseridas na dinâmica global, funcionam como novos pontos de conectividades e de mobilidade. Foram necessárias mudanças nas cidades para que nessas pudessem se estabelecer e desenvolver o conjunto de atividades requeridas para o funcionamento das filiais globais:

1) serviços de produção, em especial financeiros, jurídicos, de consultoria, publicidade, informática, engenharia e arquitetura; 2) tarefas de direção, gestão, coordenação e controle das filiais das redes globais e nacionais; 3 ) atividades industriais relacionadas e/ou a serviço das redes globais; 4) atividades de distribuição e comercialização de produtos globais destinados ao consumo das famílias e das empresas; 5) um conjunto de atividades relacionadas ao mercado imobiliário e a industria da construção ${ }^{1}$ (MATTOS, 2010, p.90).

Porém, a distribuição da rede global se deu de forma desigual nas diferentes partes do mundo. A escolha locacional de um território, mais adequado para sua valorização, aponta a preferência por áreas melhor posicionadas na rede global de cidades. Desta forma, a rede global e a distribuição física dos processos produtivos acarretaram uma dispersão e uma cobertura geográfica desigual, cujos grandes beneficiários foram os países mais desenvolvidos, ao contrário dos países latino-americanos, que se articularam de maneira desigual e, em geral, insatisfatória (MATTOS, 2010).

Internamente, as cidades se modificaram também frente às novas possibilidades de mobilidade. A cidade moderna, com a característica separação entre a moradia e o local de trabalho, originada com a revolução industrial e agravada com o zoneamento modernista, deu lugar a uma mobilidade crescente. A criação de novos meios de transporte e comunicações e os processos de reestruturação industrial permitiram o deslocamento das indústrias para locais mais distantes, acarretando no aumento dos deslocamentos moradia-trabalho (movimentos pendulares) (CAPEL, 2003).

$\mathrm{Na}$ América Latina, essa ampliação da mobilidade gerou diversos problemas, visto que o transporte de passageiros é fortemente realizado de forma individual (automóvel) e os transportes coletivos são insuficientes (PRADILLA, 2014). Embora alguns países, como a Colômbia, tenham investido no desenvolvimento de sistemas de transporte coletivos (metro-ônibus), grande parte das políticas públicas latino-americanas

\footnotetext{
${ }^{1}$ Tradução nossa do original em Espanhol: "i) servicios a la producción, en especial financieros, jurídicos, de consultoría, publicidad,informática, ingeniería y arquitectura, etc.; ii) tareas de dirección, gestión, coordinación y control de las fi liales de las redes globales y de las redes nacionales en proceso de glo-balización; iii) actividades industriales relacionadas y/o al servicio de las redes globales; iv) actividades de distribución y comerciali-zación de productos globales destinados al consumo de las familias y de las empresas; y v) un conjunto de actividades relacionadas con los negocios inmobiliarios y la industriade la construcción" (MATTOS, 2010, p.90).
} 
ainda privilegiam o automóvel (construção de infraestruturas viárias, pontes, viadutos, incentivos fiscais à produção e compra de veículos). Hoje, os temas da mobilidade e da conectividade são muito presentes nos discursos dos governos urbanos, pois o tempo de deslocamento e os meios de transporte chegaram a níveis críticos (PRADILLA, 2014). O problema da mobilidade foi agravado ainda em um contexto de segregação espacial no qual os maiores deslocamentos emprego-moradia são aqueles realizados pelas famílias de menor renda.

Aliado a isso, na América Latina a globalização acarretou em uma desvalorização da força de trabalho assalariada, com a redução do salário real, a flexibilização da relação laboral, a fragmentação da jornada laboral (PRADILLA, 2014) e a ampliação dos empregos precários e fixos descontínuos (CAPEL, 2003). Em 2002, o trabalho informal na América Latina correspondia a 46,5\% (TOKMAN apud PRADILLA, 2014) do total da população economicamente ativa, concentrando-se, principalmente, no setor terciário (PRADILLA, 2014). Além disso, ocorreu uma polarização entre a precarização dos setores médios e o aumento da necessidade de trabalhadores escassamente qualificados no setor terciário, versus uma crescente necessidade de trabalhadores altamente qualificados (JANOSHCKA , 2002). O aumento do desemprego, a multiplicação da informalidade e a exacerbação da pobreza neste período, na América Latina, acarretaram alterações na estrutura urbana, com a multiplicação das concentrações de atividades informais nas vias públicas, a multiplicação da delinquência incidental e a ampliação dos territórios de violência crescente (PRADILLA, 2014).

\section{b) A constituição da cidade difusa e fragmentada}

O processo atual de urbanização se distancia da cidade industrial precedente sendo marcado pelo aparecimento de uma nova forma urbana: a cidade difusa (CAPEL, 2003; MATTOS, 2010). Conforme descrito por Capel (2003, p.200), as novas metrópoles são caracterizadas pelo "crescimento contínuo e por sua extensão para a periferia".

Capel (2003) salienta que as mudanças na urbanização são diversas, conforme a escala que se observa: a) na escala pequena, dos países ou continentes, há a tendência a uma concentração urbana continua, com processos circulares e acumulativos de reforço das áreas urbanas existentes (primeiramente das grandes cidades, seguidas das regiões metropolitanas); b) na escala municipal / metropolitana ou regional há uma evidente dispersão da urbanização, a aparição da cidade difusa. Essa difusão urbana está relacionada com o aumento dos preços dos terrenos nos centros consolidados; com as estratégias do capital imobiliário (criação de habitação periférica em solo mais barato); com a busca por melhor qualidade de vida; com a venda do espaço rural (CAPEL, 2003).

Borsdorf (2003), estudando o desenvolvimento urbano latino-americano, identifica essa tendência de dispersão das atividades e denomina as cidades da fase de urbanização que se segue à década de 1970 de "Cidades Fragmentadas", como se vê na Fi- 
gura 1. O autor identifica uma tendência à organização setorial-linear, com, por um lado, uma acentuação das estruturas lineares (seguindo as autopistas), e, de outro, com estruturas de nós fragmentados dispersos no perímetro urbano. Essa fragmentação urbana também é percebida na distribuição das áreas industriais e centros comerciais, agora dispersos pelo território (seguindo as principais vias), e está articulada a um processo de segregação urbana (aumento dos bairros e conjuntos fechados).

Figura 1 - Modelo de desenvolvimento estrutural de uma cidade latino-americana

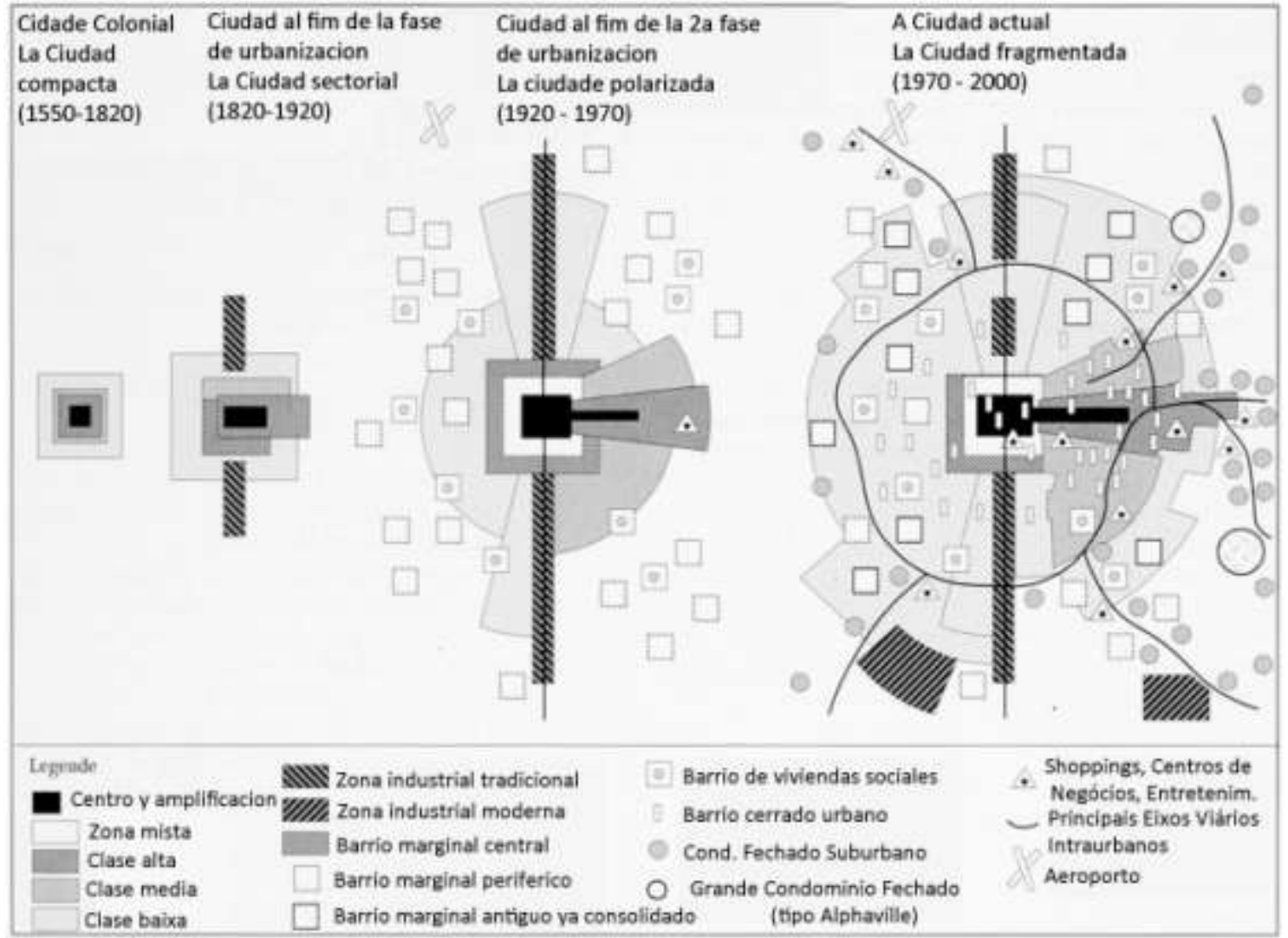

Fonte: Borsdorf, Bahr \& JANOSHCKA (2002), adaptado por Borsdorf, 2003.

\section{c) Novos comportamentos locacionais, auto-organização e a formação de ilhas urbanas}

As mudanças nos padrões locacionais ocorridas nas últimas décadas englobaram, além das empresas, também as famílias residentes nas grandes aglomerações. Estas mudanças foram impulsionadas pela/o: 1) ampliação e reconfiguração do campo metropolitano de externalidades (difusão das TICs, ampliação da intensidade de conectividade e de mobilidade) reduzindo o fator distância nas decisões locacionais desses grupos e permitindo novas escolhas; 2) mudanças no campo da governança urbana regida por uma crescente influência do princípio de subsidiariedade estatal, ampliando a liberdade de escolha das localizações em um território urbano mais extenso; 3 ) significativo e persistente aumento de ofertas imobiliárias (novas localizações, novos produtos, ênfase na incorporação de áreas periurbanas) (MATTOS, 2010). 
As empresas tendem a se dispersar nas grandes aglomerações urbanas. Muitas vezes, não se localizam diretamente no centro da metrópole (mais congestionada, contaminada e com custo elevado do solo), mas se aproveitam das condições favoráveis de uma localização mais distante (em busca de terrenos maiores e com menor valor do solo), porém dentro da área de expansão da aglomeração (MATTOS, 2010). Essa transformação implica na separação das tarefas de direção / gestão dos processos produtivos. Além disso, Capel (2003) aponta que o deslocamento das indústrias para fora dos centros urbanos provocou também mudanças nos meios de transporte e nos modos de urbanização residencial.

Em relação às famílias, vê-se uma tendência à metropolização expandida que se apresenta de forma diferente conforme a renda, porem convergindo para a ocupação de espaços suburbanos, agora não apenas destinados as classe mais baixas, mas também as de média e alta renda. Na América Latina esse fenômeno causou situações em que periferias ou assentamentos em processo de integração com as metrópoles alcançam taxas de crescimento populacional muito superiores à média urbana e, ao contrário, diversas áreas centrais possuem taxas muito baixas ou negativas (PRADILLA, 2014). As migrações intrametropolitanas têm desempenhado, assim, um papel importante no processo de transformação das aglomerações metropolitanas (HIDALGO, 2008).

As estratégias locacionais das famílias de média e alta renda incluem o modelo de urbanização dos loteamentos e condomínios fechados, a exemplo do Nordelta ${ }^{2}$ em Buenos Aires, Alphaville em São Paulo, ou diferentes empreendimentos em Santiago do Chile (JANOSHCKA, 2002; HIDALGO, 2008). Espaços que são "verdadeiras cidades satélites privadas" (MATTOS, 2010, p. 95), casos de autossegregação periférica. A seleção de trabalhos feita por Janoshcka (2002) indica que as metrópoles de Quito, Lima, Santiago do Chile e diversas cidades do México e do Brasil, também apresentam situações similares. No caso de Buenos Aires, por exemplo, embora os condomínios fechados já existissem desde os anos 1980, foi a partir dos anos 1990 que eles se converteram em fatores primários da expansão espacial e um número cada vez maior de pessoas passou a viver em áreas residenciais muradas, que não são acessíveis a todos (JANOSHCKA, 2002).

Em relação às famílias de baixa renda, observa-se um deslocamento para as áreas urbanas periféricas muitas vezes sem urbanização e que possuem menor valor da terra. A localização periférica das habitações sociais já não engloba apenas as áreas imediatas à cidade, mas os espaços limítrofes às áreas metropolitanas propriamente ditas (HIDALGO, 2008). Essa ocupação foi gerada tanto pelas políticas habitacionais, de países como o Brasil, Chile ou México ${ }^{3}$ (MATTOS, 2010; MELCHIORS; ALMEIDA,

\footnotetext{
${ }^{2}$ Bairro fechado com área residencial, infraestrutura, serviços comuns e cultura em uma área de 1.600 hectares destinada a uma população de cerca de 80.000 pessoas separadas do restante da cidade por forte sistema de segurança (JANOSHCKA, 2002).

${ }^{3}$ No Brasil, a exemplo das políticas habitacionais implantadas no México e no Chile a algumas décadas, o programa Minha Casa, Minha Vida (2009-2014), principal programa habitacional do país, tem contribuído forte-
} 
2015), como pelo mercado informal (ABRAMO, 2007). No Chile, entre 1978 e 2003, foram construídas cerca de 27.000 unidades nas comunas da periferia, sendo quase a metade construída na última década (HIDALGO, 2008). No Brasil, mais de 1.000.000 de moradias foram construídas entre 2009 e 2014 como fruto das políticas habitacionais, situadas, em grande parte, nas periferias urbanas (MELCHIORS; ALMEIDA, 2015).

As novas políticas neoliberais destinadas à habitação para a baixa renda colocaram o Estado no papel de apoiador do capital imobiliário, a partir do qual os beneficiários adquirem seus imóveis mediante subsídios ou financiamentos públicos. Como resultado, vê-se situações de excesso de moradias, como no caso do México, com uma séria crise no setor, derivada da ausência de compradores para essas habitações, falta de pagamento dos financiamentos, péssima qualidade construtiva e má localização dos empreendimentos em relação às cidades (PRADILLA, 2014). No Brasil observamse problemas semelhantes, somados aos acarretados pela violência que tomou conta de diversos conjuntos implementados pela política habitacional mais recente ${ }^{4}$ (ROLNIK, 2014).

Essa distribuição habitacional está fortemente associada à segregação sócioterritorial característica das cidades Latino Americanas. Como salientado por Pradilla (2014), nesse cenário, a segregação foi incrementada a partir da multiplicação dos loteamentos e conjuntos cercados de média e alta classe, pelo isolamento territorial dos mega conjuntos de baixa renda e pelos guetos de violência urbana, criando uma fragmentação sócio-territorial, que implicou na ampliação da desigualdade social, da segregação territorial e das barreiras físicas e sócio-culturais.

Uma das características específicas das cidades latino-americanas, que as diferenciam estruturalmente das cidades dos países hegemônicos, é a coexistência dos mercados formal e informal do solo (ABRAMO, 2007; PRADILLA, 2014). O mercado informal é um impulsionador da urbanização que contribui para a expansão urbana, ocupando terrenos, geralmente periféricos, para a autoconstrução de habitação de baixa renda ${ }^{5}$.

A globalização, na América Latina, gerou mudanças internas na distribuição territorial, com a periferização da habitação social construída pelo capital imobiliário, em mega conjuntos, ou gerada por ocupações irregulares e autoconstruções. Observouse também o esvaziamento da população das áreas centrais e dos corredores terciários, nos quais a habitação foi substituída por comércio e serviços e megaprojetos imobiliários mistos com atividades empresariais e habitacionais destinados às rendas mais altas (PRADILLA, 2014).

mente para a expansão urbana fragmentada com a construção de loteamentos de grande porte nas periferias urbanas do país (MELCHIORS, 2014).

${ }^{4}$ O programa Minha Casa, Minha Vida tem sofrido fortes críticas pelo modelo adotado e pelos efeitos identificados até o momento. Ver: Cardoso, 2013; Rolnik, 2014; Melchiors, 2014.

${ }^{5}$ Segundo o Programa de las Naciones Unidas para los Asentamientos Humanos - UN-HABITAT (apud HIDALGO, 2008), 130 milhões de latinoamericanos viviam em assentamentos precários e informais em 2006, sem ter título de propriedade nem acesso legal a serviços (PNUD, 2006). 
Os padrões de estruturação urbana da América Latina são determinados pelas lógicas de formação das rendas do solo urbano, tanto em territórios periurbanos ou intersticiais metropolitanos, como nas áreas já integradas, nas quais se articulam as velhas e novas condições estruturais de acumulação do capital (PRADILLA, 2014). Vêse, como exemplo desses padrões, as estratégias do capital imobiliário-financeiro de produzir habitação social nas periferias afastadas para reduzir custos do solo, transformando solo rural em urbano e elevando as rendas dos terrenos para a construção dos projetos, ou nas infraestruturas viárias produzidas pelo Estado ou pelo setor privado, que impulsionam o fracionamento e a construção do solo adjacente (PRADILLA, 2014). Mattos (2010, p.98) salienta que o novo padrão de urbanização pode ser sintetizado na imagem de uma "coexistência, às vezes conflituosa, de múltiplas cidades em um território de uma metrópole cuja sociedade vai se diversificando e complexando" ${ }^{16}$ e na qual existe uma crescente diferenciação sócio-residencial, produto de velhos e novos processos de segregação (guetos para ricos e pobres).

Para Pradilla (2014), o capital imobiliário-financeiro se utiliza de distintas estratégias para expandir "quase sem limites" as cidades: adquirindo terrenos e construindo habitações para distintos setores sociais (baixa renda em mega-conjuntos de microhabitações nas periferias ou para alta renda em empreendimentos cercados e segregados) e, ao mesmo tempo, reconstruindo áreas centrais com seus produtos emblemáticos (megaprojetos de renovação urbana, centros comerciais, torres de uso misto), apoderando-se assim dos incrementos das rendas do solo gerados coletivamente pelo crescimento metropolitano (PRADILLA, 2014, p.46). Em alguns casos a expansão urbana pode ser cíclica, a exemplo da Zona Metropolitana do México (expansão consolidação - nova expansão territorial) em que, após um momento de expansão, se sucedeu um segundo momento de saturação dos terrenos intersticiais deixados livres no primeiro momento expansivo (PRADILLA, 2014).

Essa urbanização integrada à atuação do capital potencializa a transformação do urbano em um espaço excludente, sobretudo para aqueles que não tem condições de se inserir na lógica de produção, porque não conseguem ser consumidores dos produtos imobiliários (HIDALGO, 2008). Os efeitos desse processo são espaços metropolitanos fragmentados e segregados, dispostos como "ilhas" funcionais de alto padrão (com alto nível de serviços, consumo, infraestrutura e lazer), que se contrastam com outras áreas, precárias, ambas construindo um espaço em contínua expansão. Nesse sentido, Mattos (2010, p. 100) considera que:

quando se observa o resultado da evolução das grandes metrópoles latinoamericanas, o que se encontra são conglomerados em contínua e descontrolada expansão, aonde aparecem múltiplos e diversos âmbitos sociais, visivelmente contrastados entre si, que funcionam de forma fragmentada, como se fossem ilhas procedentes de diferentes realidades geográficas,

\footnotetext{
${ }^{6}$ Tradução nossa do original em Espanhol: a "la coexistencia, a veces conflictiva, de múltiples ciudades en el territorio de una metrópolis cuya sociedad se ha ido diversificando y complejizando" (MATTOS 2010, p.98).
} 
mas que agora formam parte de um mesmo arquipélago.

Janoshcka (2002), de maneira semelhante, identifica quatro estruturas insulares que se converteram nos elementos determinantes da transformação e do desenvolvimento urbano latino americano: 1) ilhas de riqueza (condomínios urbanos destinados às classes média e alta, localizados na área urbana ou na área suburbada na forma de bairros privados e mega projetos); 2) ilhas de produção (distinguindo-se em áreas industriais novas (desenvolvidas e comercializadas de forma privada) e áreas anteriores, existentes nos grandes eixos industriais, agora reformadas e revalorizadas; 3 ) ilhas de consumo (centros urbanos de compras recém construídos, centro que reciclam a infraestrutura existente e "templos" suburbanos de consumo); 4) ilhas de precariedade (bairros informais centrais e periféricos e bairros de habitações sociais) (ver Figura 2).

Figura 2 - O novo modelo de uma cidade latino-americana

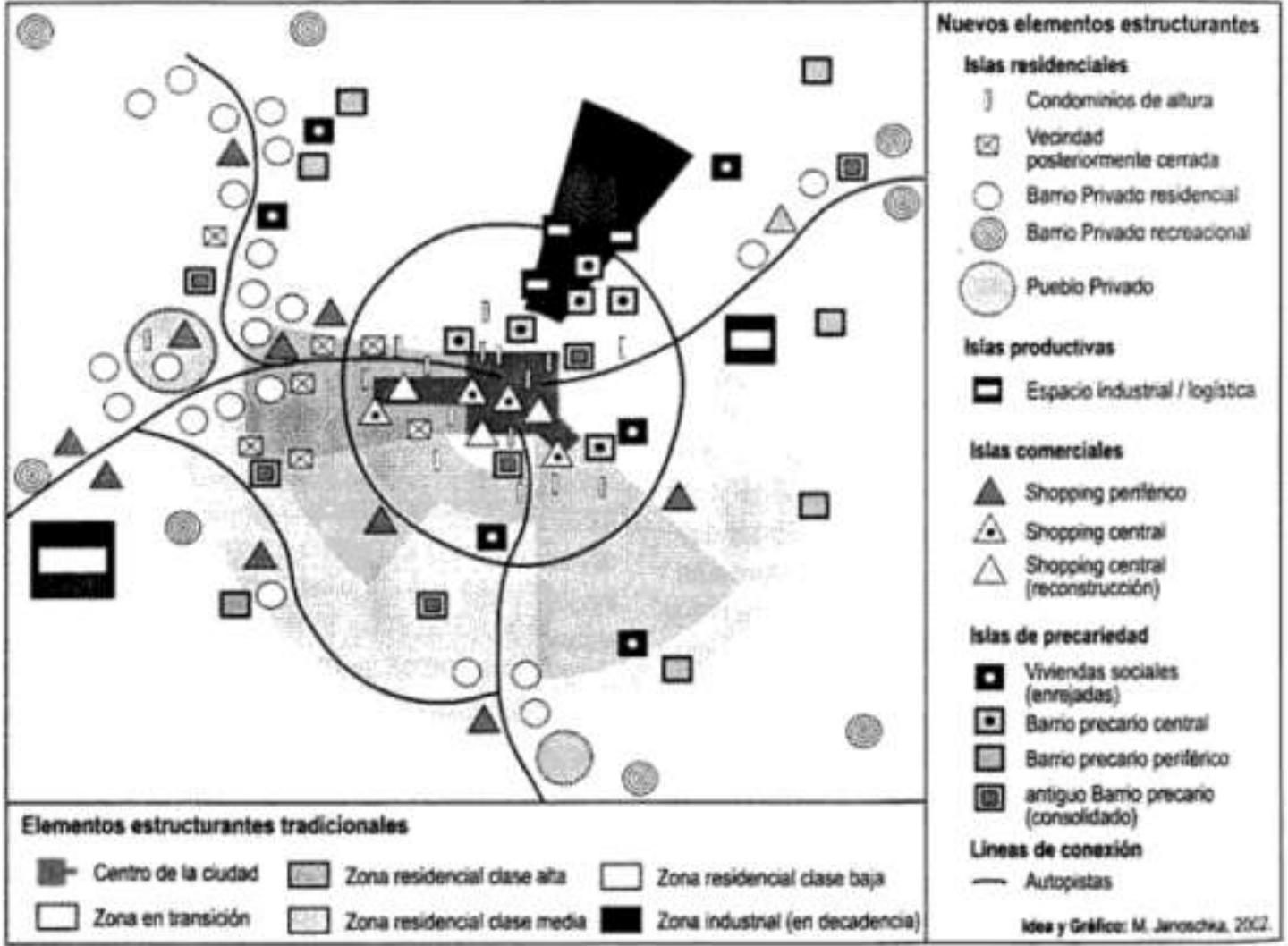

Fonte: Diagrama extraído de JANOSHCKA, 2002.

Outros estudos na área da habitação também indicam essa tendência a crescente fragmentação do espaço ilustrada por Janoshcka (2002). Em Santiago do Chile, Hidalgo et al. (2008) estabelecem uma análise das dualidades entre os dois principais modelos de urbanização intra urbanos criados a partir da adoção de ideologias neoliberais junto ao Estado-nação e ao mercado imobiliário: a privatópolis imobiliária e a 
precariópolis Estatal. A privatópolis imobiliária está relacionada ao aumento dos limites espaciais na promoção e construção de espaços residenciais fechados, cercados por barreiras de proteção e segurança, em progressiva autosegregação. Nesses empreendimentos as periferias de hoje são espaços propícios para a sua reprodução, pois dispõem de muitos metros quadrados livres com baixo valor do solo e são, atualmente, espaços muito melhor conectados pelo sistema de autopistas (HIDALGO, 2008). A precariópolis Estatal corresponde a um espaço monofuncional, segregado e fragmentado, definido pela presença de alguns serviços urbanos (eletricidade, água, luz elétrica e algumas vias pavimentadas), mas em que estão ausentes outros serviços básicos ou não (escolas, centros de saúde, áreas de lazer, centros de comércio, etc). Nessas áreas a população de baixa renda vive segregada, sem a convivência com outras classes sociais, em habitações em pequeno porte (geralmente inferiores a $\left.45 \mathrm{~m}^{2}\right)$.

Conforme apontado por Janoshcka (2002), pode-se entender que a América Latina é marcada por um cenário em que se destaca uma mescla social na macroescala, porém, na microescala se reforça um padrão segregatório.

\section{d) Policentrismo e mudanças na estrutura metropolitana}

Nas últimas décadas, além do surgimento da urbanização difusa, viu-se uma nova estrutura física dos conglomerados urbanos se desenhando: o policentrismo. As TICs, os automóveis e a ampliação das possibilidades de escolhas locacionais, permitiram e favoreceram a dispersão territorial, a intensificação da mobilidade e a transição para uma forma urbana diferente da característica do período industrialdesenvolvimentista. Essas condições favoreceram uma expansão intensa, dando forma a uma "aglomeração expandida, difusa, descontínua, policêntrica e de dimensão regional" (MATTOS, 2010, p. 96).

Nesse cenário, novas subcentralidades ganharam relevância na organização e no funcionamento da forma urbana emergente. Essas incluem as modalidades que resultam do fortalecimento, diversificação e ampliação de atividades comerciais tradicionais para o consumo cotidiano local (muitas vezes lineares acompanhando as principais vias) até os novos centros de negócios e grandes projetos imobiliários de uso misto (MATTOS, 2010). Essa dinâmica pode ser observada tanto em grandes metrópoles (São Paulo, México, Buenos Aires, Lima, Santiago do Chile), como também em metrópoles de menores dimensões (Belo Horizonte, Cidade do Panamá, Córdoba, Medellin, Montevideo, Porto Alegre, etc) nas quais se verifica a articulação funcional e essa urbanização expandida (MATTOS, 2010). O deslocamento dos centros empresariais pode ser verificado, por exemplo, em cidades como São Paulo, México, Lima, Bogotá e Santiago do Chile, nessa última, deslocando-se parte do centro de negócios até culminar na criação de uma Cidade Empresarial, em um bairro inacessível até poucas décadas atrás (MATTOS, 2010).

O deslocando das atividades de comércio, escritórios e lazer para novas áreas (de- 
socupadas e agora acessíveis) influenciou o desenvolvimento de subcentros periféricos que alteraram a dinâmica de mobilidade existente nas regiões metropolitanas. Assim, a periferia se tornou mais complexa e diversificada e a centralidade que existia anteriormente apenas no município polo, deslocou-se, gradualmente, para outros municípios da aglomeração metropolitana, alterando fluxos tradicionais da periferiacentro, agora complementados por outros fluxos internos do próprio espaço periurbano (CAPEL, 2003; MATTOS, 2010):

o novo padrão de urbanização se expressa como uma área metropolitana expandida, em que coexistem diversas subcentralidades articuladas por novas modalidades de conectividade e mobilidade em um território predominantemente urbano de dimensão regional ${ }^{7}$ (MATTOS, 2010, p. 92).

Com o aumento da conectividade e da mobilidade regional, as cidades de médio e pequeno porte, inseridas nas áreas de influência metropolitana, passaram por um incremento progressivo, visto que sua articulação com o sistema central também se intensificou (MATTOS, 2010). Na América Latina vê-se esse fenômeno em diversas áreas metropolitanas. No caso da megacidade do México houve uma tendência à dispersão urbana policêntrica que englobou pequenas cidades e periferias rurais em um sistema metropolitano cada vez mais amplo e complexo (AGUILAR, 2005; MATTOS, 2010). Nesse caso, a maior parte do crescimento hoje já não ocorre no perímetro urbano, mas em cidades de médio e pequeno porte que estão dentro de uma região metropolitana ampliada, algumas a uma distância considerável do núcleo central da megacidade (JANOSCHKA, 2005; MATTOS, 2010). No Brasil, em diversas regiões metropolitanas viu-se, nas últimas décadas, o crescimento significativo populacional e econômico das cidades médias e em regiões metropolitanas. Na região metropolitana de São Paulo, por exemplo, vê-se um elevado grau de integração técnica e funcional entre suas partes (cidades do ABC Paulista) (MATTOS, 2010).

\section{e) Redes: bases do sistema atual}

As metrópoles e a economia atual se baseiam em redes. Redes físicas de vias, abastecimento, energia, transporte, redes de intercambio de informações - correios, fibra; e redes econômicas que se articulam globalmente, desconsiderando as fronteiras locais e nacionais, buscando conexões, muitas vezes, não com seu entorno imediato, geográfico, mas com múltiplos lugares conectados pelas suas especialidades (MATTOS, 2010). O que se vê é:

um mosaico ou arquipélago de grandes cidades-regiões [que] constituem uma das principais redes estruturais da nova economia global, funcionando

\footnotetext{
${ }^{7}$ Tradução nossa do original em Espanhol: "área metropolitana expandida, en la que coexisten diversas subcentralidades articuladas por nuevas modalidades de conectividad y movilidad en un territorio predominantemente urbano de dimensión regional" (MATTOS, 2010, p.92)
} 
como plataformas territoriais a partir das quais grupos concentrado ou redes de empresas disputam os mercados globais ${ }^{8}$ (MOURA; FIRKOWSKI, 2007, p. 127).

As metrópoles, inseridas no processo de globalização, assumem papéis nessa rede global, destacando-se por possuírem mais infraestruturas e serviços, potencial inovador e recursos humanos melhor qualificados e diversificados. Fatores como o grau de fiscalização, legislações trabalhistas e outros mecanismos de controle do mercado de trabalho também afetam a atratividade e a competitividade de um território nas escolhas locacionais das empresas.

A importância de cada cidade, ou componente desta rede, aumenta ou diminui também de acordo com a posição que seus respectivos países possuem nos circuitos globais dominantes (MATTOS, 2010). Distintas áreas urbanas não tem o mesmo potencial de atração dos fluxos e recursos mundiais, o que resulta em desigualdades de condições entre as cidades nesta disputa global. O estudo "Global and World Cities Group and Network" (GaWC) avaliou a importância relativa das principais cidades do mundo em função da capacidade que cada uma tem de prestar os serviços requeridos pelas empresas transnacionais. A pesquisa aponta que na América Latina as principais áreas urbanas estão inseridas no processo de globalização, mas com uma distribuição hierárquica muito desigual, desempenhando um papel secundário na rede, visto que seus respectivos países também ocupam papel secundário em avaliações de globalização, risco-país e competitividade (MATTOS, 2010). Os lugares de ponta na rede mundial são ocupados pelos países do hemisfério norte (América do Norte, Europa e Ásia).

Fala-se hoje de um 'urbanismo das redes', 'networked city' (CAPEL, 2003). O crescimento e o funcionamento das áreas metropolitanas também se apoia na existência de redes, que articulam o território e são resultado da interação entre os múltiplos atores (públicos e privados, econômicos, políticos e técnicos, mas não são de acesso universal. São também construídas muitas vezes a serviço da promoção imobiliária e não atendem os diversos segmentos sociais da mesma maneira (CAPEL, 2003).

\section{f) Morfologia Latino Americana: entre favelas e arranha-céus}

Na visão de Capel (2003) a morfologia utilizada nas expansões metropolitanas latino-americanas não sofreu profundas modificações em relação aos estudos históricos. Vê-se atualmente cidades que são uma mescla de: tecidos urbanos configurados, áreas residenciais de baixa densidade, áreas irregulares de favelas e autoconstrução, centros históricos com processos de renovação urbana e processos de gentrificação, bairros fechados, cenários em rede - espaços morfológicos para infraestrutura de

\footnotetext{
${ }^{8}$ Tradução nossa do original em Espanhol:"[...] un mosaico o archipiélago de grandes ciudades-regiones constituyen una de las principales redes estructurales de la nueva economía global, funcionando como plataformas territoriales a partir de las cuales grupos concentrados o redes de empresas disputan los mercados globales" (MOURA; FIRKOWSKI, 2007, p. 127).
} 
comunicação, elementos arteriais e nós.

Observa-se ainda a expansão dos condomínios fechados, com mudanças nas formas de segregação sócio-espacial e a produção de grandes torres em altura no interior das aglomerações urbanas (edifícios coorporativos das grandes empresas, residenciais, de escritórios ou hoteleiros), intervenções que estão diretamente relacionadas às necessidades de recuperação das áreas centrais e com as renovadas estratégias do capital financeiro, que aponta os negócios imobiliários em busca de rentabilidades com maior velocidade de retorno (Hidalgo, et al. 2008). A tendência à verticalização, muitas vezes, está associada à utilização de uma tipologia generalizada, sem muitas variações ou características peculiares de cada metrópole, criando um cenário similar para muitas das grandes cidades do mundo (MATTOS, 2010).

Algumas características são particulares do cenário latino-americano: a existência de áreas controladas pelo crime organizado e de áreas autoconstruídas (fruto da atuação do mercado informal do solo), geralmente periféricas, coexistindo com áreas ocupadas pela classe média e alta, muitas vezes muradas e protegidas para separá-las dos bairros de baixa renda. Uma cidade fragmentada, que ocorre como uma nova forma de separação de funções e elementos sócio-espaciais:

elementos econômicos de luxo se localizam em bairros pobres; centros de comércio situados em todas as partes da cidade; bairros marginais entrando nos setores da classe alta. Esse desenvolvimento se faz possível somente através de muros e cercos, barreiras com que se separam e asseguram contra a pobreza as ilhas de riqueza e exclusividade ${ }^{9}$ (BORSDORF, 2003, p. 44).

Esse modelo de urbanização tende à expansão da ocupação urbana que altera as dinâmicas existentes nas áreas rurais, o meio ambiente e a paisagem natural. Já no início do Séc XX se discutiam os processos de expansão das metrópoles e pensava-se seus efeitos sobre o ambiente (CAPEL, 2003). Nesse sentido, cabe refletir sobre os padrões existentes nas metrópoles da América Latina que mesclam uma contínua expansão urbana, aliada aos contrastes sociais de um ambiente fragmentado e segregado que divide o espaço com a existência de favelas e áreas de alta concentração de riqueza.

\section{g) Instrumentos de planejamento urbano: seu lugar e valor no momento atual}

A década de 1970 marcou o início do movimento "contra planos", gerando um cenário que desvalorizou o planejamento urbano e enfatizou o projeto, contribuiu para a valorização das ações setoriais e para o urbanismo pensado caso a caso, com acordos entre a administração pública e o mercado imobiliário (CAPEL, 2003). Essa ênfase

\footnotetext{
${ }^{9}$ Tradução nossa do original em Espanhol: "Elementos econômicos de lujo se localizan en bairros pobres; centros de comercio se emplazan en todas partes de la ciudad; bairros marginales entran en los sectores de la clase alta. Este desarollo sa hace possible solamente a traves de mudos y cercos, barreras con que se sepran y asseguran contra la pobreza las islas de riqueza e exclusividad (BORSDORF, 2003, p. 44).
} 
em uma "desregulação" significou uma tendência à urbanização estendida e com escasso controle.

Embora o planejamento urbano adotado no período anterior, modelado pelo padrão de acumulação com a intervenção do Estado, tivesse legitimidade, sua prática real no ordenamento racional do solo urbano foi limitada e insuficiente para enfrentar o crescimento urbano acelerado resultante da ação individual, espontânea e dos múltiplos atores urbanos (PRADILLA, 2014). Muitas vezes foi pensado como documento estático, e não como um processo permanente e dinâmico, ou foi frágil e modificado a cada mudança de governo, carecendo de continuidade maior, sendo subordinado aos interesses dos setores hegemônicos e do capital imobiliário, sem contar com a participação cidadã (PRADILLA, 2014).

Porém, nas últimas décadas, com o padrão de acumulação neoliberal, esse processo se agravou. Desapareceu a legitimidade do planejamento frente à ideologia política dominante (PRADILLA, 2014). A diluição do Estado, que deixou de ter um papel controlador adotando uma postura facilitadora, e o novo papel assumido pelo capital imobiliário-financeiro (nacional e estrangeiro), com livre iniciativa dos mercado, alteraram a força dos agentes e causaram profundas modificações no espaço urbano. Pradilla (2014, p. 51) aponta que mesmo que alguns planos de desenvolvimento urbano tenham sido elaborados nesse período, sejam por questões legais ou de legitimação discursiva e ideológica, "sua eficácia e operacionalidade desaparece no ar frente às novas condições de funcionamento do Estado capitalista":

As políticas urbanas dos governos locais respondem aos imperativos neoliberais, ideológicas ou reais, do livre comércio, da globalização, da concorrência entre cidades, da rentabilidade do território, da vocação terciária [...] $\mathrm{Na}$ verdade, se submeterm às razões ou ditames do capital e seus lobistas: a uma crescente privatização e mercantilização do urbano, a rentabilidade dos negócios urbanos, al capital imobiliário-financeiro como facção dominante na produção de urbano e suas intervenções, aos interesses da transnacional automotiva, etc, ainda que tenham que afetar aos setores majoritários ou aos setores médios e altos em seus bairros e distritos ${ }^{10}$ (PRADILLA, 2014, p. 51).

Acresce-se à desvalorização do planejamento e a redução do papel do Estado, a complexidade crescente nas aglomerações metropolitanas que demandam, cada vez

\footnotetext{
${ }^{10}$ Tradução nossa do original em Espanhol: "Las políticas urbanas de los gobiernos locales, poco diferenciadas en términos de la ideología declarada de los partidos gobernantes, se han hecho pragmáticas y en ocasiones banales, 26 responden a los imperativos neoliberales, ideológicos o reales, del libre mercado, la globalización, la competitividad entre ciudades, la rentabilidad del territorio, la vocación terciaria, la conectividad, la movilidad, la gobernanza, etc. En realidad, se someten a las razones o dictados del capital y sus cabilderos: a la privatización y la mercantilización creciente de lo urbano, a la rentabilidad de los negocios urbanos, al capital inmobiliario-financiero como fracción dominante en la producción de lo urbano y sus intervenciones, a los intereses de las trasnacionales automotrices, etcétera, aunque tengan que afectar más a los sectores mayoritarios o, aún, a sectores medios y altos en sus barrios y colonias (PRADILLA, 2014, p.51).
} 
mais, soluções a problemas que extrapolam os limites administrativos das municipalidades. As áreas metropolitanas carecem, frequentemente, de organismos de governo comuns que façam uma gestão unitária do conjunto, ultrapassando a visão fragmentada administrativamente. Agregam complexidade ao problema, as divisões administrativas e a multiplicidade de governos existentes na maioria das áreas metropolitanas, que dificultam a implementação de uma gestão metropolitana integrada.

A ruptura do modelo metropolitano centro-periferia, com a criação de novas centralidades, contribui para o surgimento de uma maior interdependência nas aglomerações metropolitanas, ao mesmo tempo que amplia problemas de identidade e cidadania metropolitana e conduz municípios menores a aumentarem suas reivindicações políticas (CAPEL, 2003). Nesse sentido, cabe ressaltar, conforme apontado por Capel (2003), que é preciso se ter em conta que o espaço metropolitano não é homogênio: existem desigualdades sociais, econômicas e de equipamentos entre os municípios integrantes de uma aglomeração e o planejamento e a gestão dessas áreas precisam considerar suas particularidades, sem perder a noção do todo (CAPEL, 2003).

\section{h) Importância da distinção e do reforço das identidades}

Existe hoje uma forte competição entre as cidades globais na busca da atração dos investimentos e das pessoas. Nessa disputa há a possibilidade de uniformização dos espaços e da paisagem urbana, com a criação de edifícios, intervenções e processos de renovação urbana padronizados nas diferentes partes do mundo.

Considerando-se este cenário, os atrativos específicos e, portanto intransferíveis, de cada cidade (entorno natural, tipo peculiar de vida urbana, sua cultura, música, arquitetura, equipamentos sociais) podem criar vantagens competitivas, únicas, se conservados e orientados como estratégias para melhorar a competitividade (MATTOS, 2010). Nesse sentido, salienta-se que essas qualidades identitárias devem ser preservadas, fortalecidas e visibilizadas criando reforços locais ao processo de globalização (MATTOS, 2010).

\section{i) Dinâmica dos movimentos sociais na metrópoles sob os efeitos da globalização}

A globalização agravou as contradições sociais urbanas e causou mudanças na função do Estado, ao mesmo tempo em que gerou um desgaste dos movimentos populares em relação às reivindicações históricas (terra, habitação e serviços) (PRADILLA, 2014). Nas últimas décadas, surgiram novas causas urbanas para a mobilização: direito à cidade, defesa contra os mega-eventos e seus impactos sobre a habitação popular, em especial no caso Brasileiro, recente, da Copa do Mundo de 2014.

Entretanto, conforme Pradilla (2014), a novidade é o surgimento de uma estreita articulação entre os governos locais e o capital imobiliário-financeiro (na produção de mega projetos urbanos públicos ou privados; grandes conjuntos de usos múltiplos e fechados; em intervenções privadas de re-produção, renovação e verticalização ur- 
bana). Essas intervenções passam a afetar também setores de média e alta renda que têm, pontual e fragmentadamente, se integrado aos movimentos de oposição ao capital imobiliário e aos governos locais (PRADILLA, 2014).

Pradilla (2014) salienta ainda duas mudanças significativas do período recente em relação à reivindicação e enfrentamentos sociais por razões urbanas ou urbanizadas: 1) a aparição de múltiplos movimentos interclassistas e/ou setoriais por reivindicações e problemas novos (igualdade de gênero, diversidade sexual, exclusão social, ecologia, deficiências físicas, violência urbana); 2) o deslocamento do discurso político, pesquisas e práticas sociais, movimentos e processos coletivos para a participação cidadã, individualizada, controlada e restringida pelo Estado, sem que este lhe outorgue um papel decisório na gestão urbana. Salienta ainda as consequências desse descolamento, buscando enfraquecer os movimentos sociais classistas e evitando, assim, a tomada de consciência de uma participação que possa transformar a sociedade e a cidade frente aos efeitos da globalização.

\section{OS RESULTADOS NAS METRÓPOLES LATINO-AMERICANAS}

Para Mattos (2010) as mudanças de estrutura, organização, funcionamento e aparência pelas quais passaram as metrópoles latino-americanas nas últimas décadas são similares às identificadas em outras partes do mundo. Pradilla (2014) acrescenta que a essas características globais há uma série de especificidades das cidades da América Latina, que ocupam um lugar secundário na esfera global e passaram por processo históricos diversos dos países hegemônicos. Borsdorf (2003), por sua vez, complementa a questão indicando que a globalização, que se sofre e se desfruta, em diferentes âmbitos (economia, política, cultura, informação e urbana), têm reforçado as redes globais influenciando fortemente as estruturas urbanas, não só no sentido de homogeneizá-las, mas também acentuando particularidades locais ou regionais.

Compartilhando-se da visão dos autores citados acima, o Quadro 1 resume os principais efeitos das transformações pelas quais passam as metrópoles da américa latina nas últimas décadas. $O$ quadro busca apresentar as transformações gerais das metrópoles nas diferentes partes do mundo, acrescentando as particularidades latino-americanas.

Quadro 1 - Principais transformações urbanas das metrópoles latino-americanas sob os efeitos da globalização

\begin{tabular}{|l|l|l|}
\hline \multirow{2}{*}{$\begin{array}{l}\text { Estrutura pro- } \\
\text { dutiva e mobi- } \\
\text { lidade }\end{array}$} & $\begin{array}{l}\text { Tendência à reestruturação dos } \\
\text { processos produtivos (subproces- }\end{array}$ & $\begin{array}{l}\text { Particularidades acentuadas no contexto } \\
\text { latino-americano }\end{array}$ \\
\hline $\begin{array}{l}\text { (filiais), dispersão das atividades } \\
\text { lariada, flexibilização da relação laboral, } \\
\text { fragmentação da jornada laboral, amplia- } \\
\text { ção dos empregos precários e fixos des- } \\
\text { contón deslocamentos pendula- } \\
\text { colarização entre precarização dos dos }\end{array}$ & \\
\hline
\end{tabular}




\begin{tabular}{|c|c|c|}
\hline & $\begin{array}{l}\text { setores médios e aumento da es- } \\
\text { pecialização no setor terciário, }\end{array}$ & \\
\hline $\begin{array}{l}\text { Organização e } \\
\text { Crescimento } \\
\text { urbano }\end{array}$ & $\begin{array}{l}\text { Ruptura do modelo centro- } \\
\text { periferia, } \\
\text { Escala global: tendência a uma } \\
\text { concentração urbana continua, } \\
\text { Escala municipal / metropolitana : } \\
\text { aumento da dispersão da urbaniza- } \\
\text { ção e aparição da cidade difusa. }\end{array}$ & $\begin{array}{l}\text { Tendência á fragmentação urbana, } \\
\text { Tendência à acentuação das estruturas } \\
\text { lineares (seguindo autopistas) e de nós } \\
\text { fragmentados dispersos no perímetro } \\
\text { urbano, }\end{array}$ \\
\hline $\begin{array}{l}\text { Comportamen- } \\
\text { tos locacionais }\end{array}$ & $\begin{array}{l}\text { Surgimento de novos compor- } \\
\text { tamentos locacionais: tendên- } \\
\text { cia à a) dispersão de empresas, } \\
\text { b) metropolização expandida } \\
\text { da habitação com a ocupação } \\
\text { de espaços suburbanos, }\end{array}$ & $\begin{array}{l}\text { Novos comportamentos locacionais, } \\
\text { tendência à formação de guetos ur- } \\
\text { banos: } \\
\text { "ilhas urbanas" para a alta renda; } \\
\text { deslocamento para a periferia, au- } \\
\text { mento dos espaços auto-organizados } \\
\text { e dos mega conjuntos habitacionais } \\
\text { para a baixa renda, } \\
\text { Coexistência dos mercados formal e } \\
\text { informal do solo, }\end{array}$ \\
\hline $\begin{array}{l}\text { Estrutura me- } \\
\text { tropolitana }\end{array}$ & \multicolumn{2}{|c|}{$\begin{array}{l}\text { Tendência a criação de uma aglomeração expandida com estruturas policêntri- } \\
\text { cas regionalmente conectadas, }\end{array}$} \\
\hline Redes & $\begin{array}{l}\text { Metrópoles e economia baseada } \\
\text { em redes que podem ultrapassar } \\
\text { fronteiras locais e nacionais, conec- } \\
\text { tadas globalmente, }\end{array}$ & $\begin{array}{l}\text { Metrópoles inseridas na rede mundial, } \\
\text { mas desempenhando papel secundário, } \\
\text { visto que seus respectivos países também } \\
\text { ocupam papel inferior, }\end{array}$ \\
\hline $\begin{array}{l}\text { Morfologia } \\
\text { Urbana }\end{array}$ & $\begin{array}{l}\text { Tendência à verticalização da cida- } \\
\text { de, }\end{array}$ & $\begin{array}{l}\text { Expansão dos condomínios fechados (ca- } \\
\text { sas e edifícios), } \\
\text { Ampliação da desigualdade social, da } \\
\text { segregação territorial e das barreiras físi- } \\
\text { cas, } \\
\text { Coexistência de áreas controladas pelo } \\
\text { crime organizado e de áreas autoconstru- } \\
\text { ídas com áreas ocupadas pela classe mé- } \\
\text { dia e alta, }\end{array}$ \\
\hline $\begin{array}{l}\text { Planejamento } \\
\text { urbano }\end{array}$ & \multicolumn{2}{|c|}{$\begin{array}{l}\text { Desvalorização dos processos de planejamento urbano e ênfase nos projetos } \\
\text { (pontuais e fragmentados), } \\
\text { Redução do papel do Estado no planejamento e produção da cidade, }\end{array}$} \\
\hline $\begin{array}{l}\text { Padronização } \\
\text { x Identidades }\end{array}$ & \multicolumn{2}{|c|}{$\begin{array}{l}\text { Cenário marcado pela competição entre as cidades globais na busca da atração } \\
\text { dos investimentos e das pessoas, } \\
\text { Qualidades identitárias, se preservadas, fortalecidas e visibilizadas criam refor- } \\
\text { ços locais ao processo de globalização, }\end{array}$} \\
\hline $\begin{array}{l}\text { Agentes e di- } \\
\text { nâmica dos } \\
\text { movimentos } \\
\text { sociais }\end{array}$ & $\begin{array}{l}\text { Estreitamento da articulação entre } \\
\text { os governos locais e o capital imo- } \\
\text { biliário-financeiro intervenções no } \\
\text { espaço urbano. }\end{array}$ & $\begin{array}{l}\text { Novas causas urbanas para a mobilização: } \\
\text { direito à cidade, defesa contra os mega- } \\
\text { eventos e seus impactos sobre a habita- } \\
\text { ção popular. }\end{array}$ \\
\hline
\end{tabular}

Fonte: Elaborado a partir das pesquisas de: Janoshcka (2002); Janoshcka (2005); Capel (2003); Borsdorf (2003); Janoschka (2005); Mattos, 2010; Hidalgo (2012); Pradilla (2014). 


\section{CONSIDERAÇÕES FINAIS}

Em sua maioria, as metrópoles atuais da América Latina seguem as determinações do padrão neoliberal de acumulação. Nas últimas décadas, essas sofreram profundas transformações, fruto das alterações do sistema econômico e das mudanças das tecnologias da informação e comunicação. Hoje, acredita-se que as metrópoles latinoamericanas são o resultado de traços herdados do passado, problemas e contradições, que se juntam a diferentes estruturas e características gerais acarretadas pelos efeitos do novo modo capitalista, criando novas particularidades à região.

A existência de uma história específica de: subsistência indígena; urbanização acelerada; industrialização tardia e desindustrialização prematura; terceirização informal; autoconstrução maciça; mercado informal do solo e da habitação altamente atuante; desemprego estrutural; pobreza; informalidade; regimes de exceção; baixa cidadania e uma violência urbana generalizada (PRADILLA, 2014), são alguns dos traços que marcam o processo de formação das metrópoles latino-americanas. A essas características históricas juntam-se agora novas transformações acarretadas pelo cenário atual, que agravam as particularidades ligadas às desigualdades sociais.

Em relação às transformações físicas, há um crescente processo de fragmentação e de segregação sócio-espacial que contribui para a formação de um território urbano que se organiza em forma de ilhas, isoladas e representativas dos interesses do capital imobiliário-financeiro. A crescente dispersão urbana, que possui elevados custos sociais, ambientais e econômicos, também aponta uma necessidade de revisão do modelo de urbanização adotado.

A atuação dos agentes na produção do espaço urbano também é fundamental para a construção das cidades. Ao Estado cabe responsabilidades importantes, entre as quais regrar as formas de ocupação do solo e a construção de infraestrutura e redes, questões extremamente importantes para o planejamento urbano das áreas urbanas e metropolitanas, porém hoje relegadas a um segundo plano. Precisa-se, cada vez mais, construir processos de concertação entre os agentes, buscando que a cidade produzida seja fruto de múltiplas visões, incluindo diferentes segmentos da população nos processos de tomada de decisão. Nesse sentido, os movimentos sociais tem papel fundamental no controle dos processos de construção da cidade, podendo estabelecer um contraponto ao modelo fortemente influenciado pela atuação do capital imobiliário-financeiro. Ao Estado cabe, também, assumir seu papel de articulador e congregador entre as diferentes visões e interesses dos diversos agentes envolvidos na construção das cidades.

O reforço das características locais também se faz relevante frente a uma tendência de padronização dos espaços. Defende-se, assim, a preservação, fortalecimento e visibilidade das particularidades de cada local a fim de possibilitar, não apenas a atração de investimentos, mas a manutenção da cultura e do patrimônio que faz de cada lugar algo único e especial. 
Discutiram-se neste texto os efeitos das transformações econômicas e tecnológicas recentes sobre as metrópoles latino-americanas analisando seus efeitos no processo contemporâneo de metropolização. Longe de pretender concluir, buscou-se identificar tendências e pontos em comum nas transformações físicas pelas quais passam as metrópoles latino-americanas na atualidade, a fim de compreender os efeitos da globalização e auxiliar as reflexões sobre o tema.

\section{REFERÊNCIAS}

ABRAMO, P. A. A Cidade COM-FUSA: a mão inoxidável do mercado e a produção da estrutura urbana nas grandes metrópoles latino-americanas. Revista Brasileira de Estudos Urbanos e Regionais (ANPUR), v. 9, N.2, Novembro 2007, p. 25-59.

AGUILAR, A. G. Articulación territorial y mobilidad laboral en la periferia regional de la Ciudad de México. In: MATTOS, C. et al., (Ed.). Gobernanza, Competitividad y Redes: La gestión en las ciudades del siglo XXI. Santiago de Chile: Instituto de Estudo Urbanos y Territoriales, 2005. p.151-172.

CAPEL, H. (2003) Redes, chabolas y rascacielos. Las trasformaciones físicas y la planificación en las áreas metropolitanas. In Capel, H. (coord) Ciudades, arquitectura y espacio urbano. Revista Mediterráneo Económico, núm. 3, pp. 199-238.

BORSDORF, A. Como modelar el desarollo y la dinâmica de la ciudad latinoamericana. EURE (santiago), Mayo, 2003, vol. 29, n 86, p.37-49.

CARDOSO, A. O Programa Minha Casa Minha Vida e seus Efeitos Territoriais. Rio de Janeiro : Letra Capital , 2013.

JANOSHCKA , M. El nuevo modelo de la ciudad latinoamericana: fragmentación y privatización. Eure (Santiago), v. 28, n. 85, p. 11-20, 2002.

JANOSHCKA, M. De ciudades dispersas a ciudades perforadas: Una nueva fase de transición demográfica y sus consecuencias morfológicas. In: MATTOS, C. et al., (Ed.). Gobernanza, Competitividad y Redes: La gestión en las ciudades del siglo XXI. Santiago de Chile: Instituto de Estudo Urbanos y Territoriales, 2005. p.151-172.

HIDALGO, Rodrigo D. et al. Tipologías de expansión metropolitana en Santiago de Chile: precariópolis estatal y privatópolis inmobiliaria. Scripta Nova: revista electrónica de geografía y ciencias sociales, n. 12, p. 109, 2008.

MATTOS, C. de. Globalizacón y metamorfosis metropolitana en América Latina. De ciudad a lo urbano generalizado. Revista de Geografia Norte Grande, 47: 81-104, 2010.

MELCHIORS, L. C. ; ALMEIDA, M. S. . Entre o sonho e a realidade: a habitação social no Brasil de uma perspectiva histórica. Arquisur Revista, v. 7, p. 46-59, 2015.

MOURA, R.; FIRKOWSKI, O. L. C. La dimensión regional de las aglomeraciones urbanas brasileñas y los retos de gestión. Pampa. Revista Interuniversitaria de Estudios Territoriales, 2007, vol. 3, № 3, p. 121-144.

PRADILLA-COBOS, E. La ciudad capitalista en el patrón neoliberal de acumulación en 
América Latina. Cadernos Metrópole. São Paulo, v.16, n.31, pp. 37-60, jun 2014. ROLNIK, R. Programa Minha Casa Minha Vida precisa ser avaliado - Nota pública da Rede Cidade e Moradia. Disponível em: https://raquelrolnik.wordpress.com Acesso em: 10 nov. 2014.

Artigo recebido em 24 de maio de 2016.

Aprovado em 01 de agosto de 2017. 